\title{
Registering Absence: Shadows as Objects
}

TITHI SANYAL

University of Michigan
Shadows contain information not otherwise evident in architectural drawings and representation. From the techniques of skiagraphy and the teachings of the descriptive geometry of the Beaux Arts period, shadows have been considered a 'mechanical procedure of projection' by many critics including Robin Evans in Architectural Projection. ${ }^{1}$ As we transition into the digital era, shadows are no longer considered deliberate design intentions but a consequence of computational algorithms through the use of rendering software. Moreover, the freedom to pan, orbit, and place light sources in a virtual space has altered our understanding of shadows and scales. The project positions shadow as a design tool by formulating a relationship between skiagraphy using orthographic projections and digital rendering of the 21st century. It investigates how shadows can evolve from a descriptive tool to a technique of generating forms.

In Beaux Art architecture drawings, shadows drafted as 45-degree projections capture the subtleties of architectural elements and spaces. Draftsman use shadows to emphasize architectural qualities of a building including texture, color, relief, proportions, and scales. American architect and educator Henry McGoodwin, known for his influential publication Architectural Shades and Shadows (1904), writes:

"The student should realize at the outset that in casting shadows on architectural drawings he is dealing with materials of art rather than with materials of mathematics. The shades and shadows of architectural objects are architectural entities, having form, mass, and proportion just as have other architectural entities." 2

Shadows thus were a descriptive tool that captured the design intentions of the period not otherwise evident in a drawing. In today's digital era, we associate shadows as outcomes of simulation. John May in Everything Is Already an Image, states that:

"the world of the post-orthographer is simultaneously an image and a model... But unlike drawing, imaging does not want to be a representation of the world, it wants to be a presentation of the world- an automatic and perceptually up to date, real-time model of the world." ${ }^{\prime 3}$

As May points out that for a post-orthographer the shadow doesn't want to limit itself to a representation. Its goal is being spatial with materiality and form. The project understands how skiagraphy operations of combining two and three-dimensional projections on plans and elevations can be assimilated into digital modeling, thereby generating newer forms.

The technique developed in translating the ephemeral nature of shadow into a permanent mass and volume is tested on the ruins of Palmyra, an archaeological site in Syria. To appreciate lost architectural information, the project utilizes drawings from early 19th century BCE compiled by the traveler Robert Wood; thereafter creating shadow objects of the missing architecture. The project no longer considers shadows as mere information, but as a physical construct that registers the absent or visually unseen. The shadow object is a fossil for architectural information.

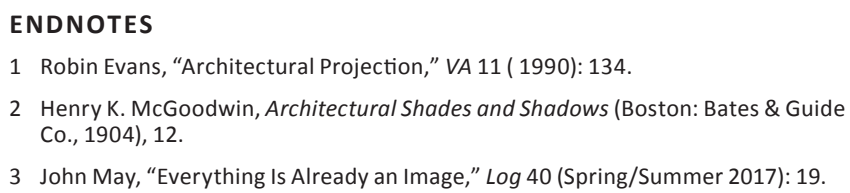


Registering Absence: Shadows as Objects

\section{Shadow as Projection}
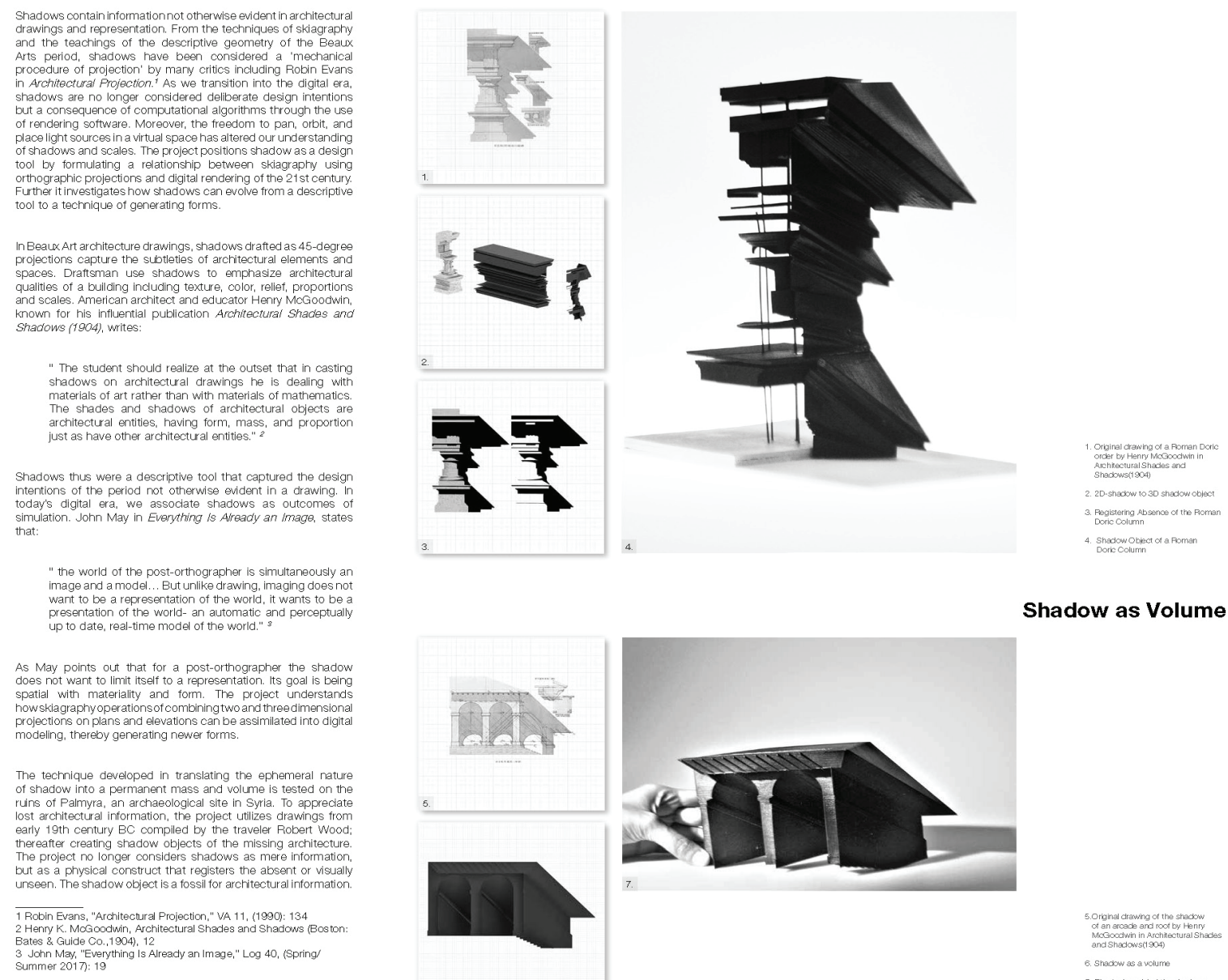

Shadow as Volume
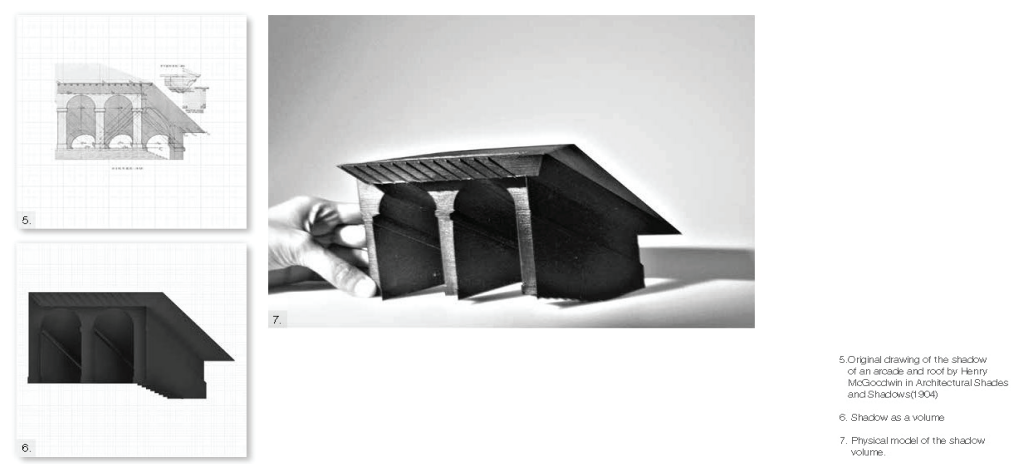

Shadow as Architecture
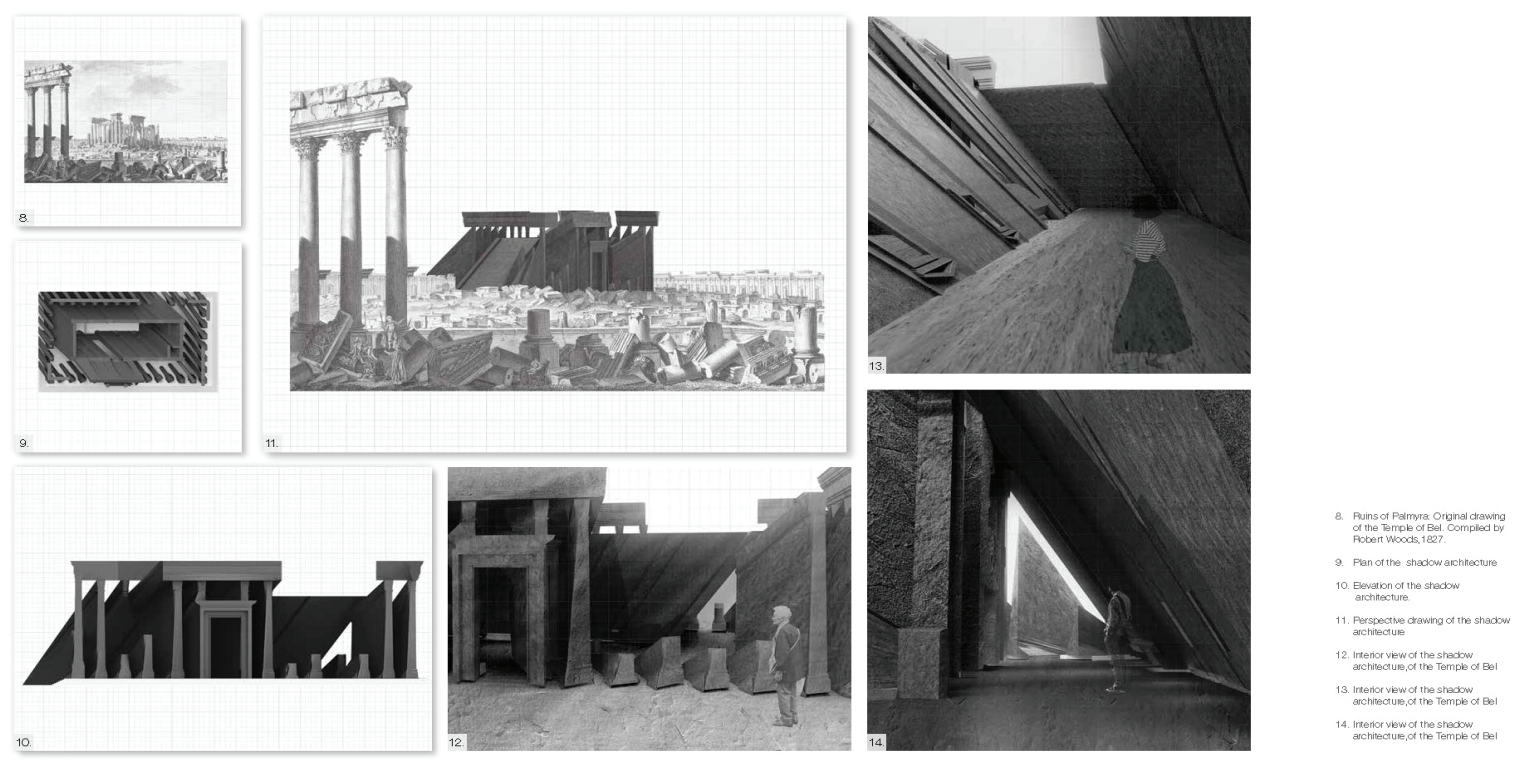